\title{
Algumas considerações sobre formação de professores e o habitus docente
}

\author{
Some considerations about teacher \\ training and teacher habitus
}

\section{Algunas consideraciones sobre la formación de profesores y \\ el habitus docente}

\section{Adriane Knoblauch, Giselly Cristini Mondardo, Luciane Aparecida Moraes Capponi*}

\section{Resumo}

O objetivo do artigo é apontar contribuições do pensamento de Pierre Bourdieu, especificamente para os estudos sobre formação de professores, profissionalização e constituição da docência. Serão apresentadas algumas considerações sobre o conceito de habitus e o processo de socialização e, em seguida, discutiremos a constituição da prática escolar que

AK: Doutora em Educação, e-mail: adrianeknoblauch@gmail.com

GCM: Mestre em Educação, e-mail: gmondardo@gmail.com

LAMC: Mestre em Educação, e-mail: lu.capponi@hotmail.com 
se converte em senso prático. As análises apontam que a docência é fruto da trajetória social composta por diferentes agências socializadoras, as quais podem ser complementares entre si ou não, o que contribui para a construção de um habitus com disposições híbridas. Outro componente que se destaca é prática educativa que, como cultura compartilhada, também é um importante elemento que compõe o habitus, a partir do qual o aprendizado ocorre e as decisões didático-metodológicas são tomadas. Ressaltamos que conceber a docência como fruto da trajetória social a partir de disposições híbridas de habitus pode se constituir como uma ferramenta importante para nossas formas de atuar em cursos de formação docente e na elaboração de políticas públicas para essa área.

Palavras-chave: Habitus. Socialização. Formação de professores.

\begin{abstract}
The purpose of this article is to point contributions of the thought of Pierre Bourdieu specifically for studies on teacher training, professionalization and incorporation of teaching. There will be presented some considerations about the concept of habitus and the process of socialization and we will discuss the establishment of school practice that converts to common sense. The analyzes show that teaching is the result of social trajectory that consists in different socializing agencies, which can be complementary to each other or not, which contributes to building a habitus with hybrid provisions. Another component is the own educational practice that as a shared culture, is also an important element that make up the habitus, from which learning takes place and educational-methodological decisions are made. We emphasize that conceiving teaching as a result of the social trajectory from hybrid dispositions of habitus can constitute an important tool for our ways of acting in teacher training courses and in the elaboration of public policies for this area.
\end{abstract}

Keywords: Habitus. Socialization. Teacher training. 


\section{Resumen}

El objetivo de este artículo es indicar las contribuciones del pensamiento de Pierre Bourdieu específicamente para los estudios sobre la formación del profesorado, la profesionalización y la constituición de la enseñanza. Presentará algunas consideraciones sobre el concepto de habitus y el proceso de socialización; luego, se discutirá la creación de la práctica escolar que se convierte en el sentido común. Los análisis muestran que la enseñanza es el resultado de la trayectoria social que se compone de diferentes agencias de socialización que pueden ser complementarias entre sí o no, lo que contribuye a la construcción de un habitus con arreglos híbridos. Otro componente que se destaca es la práctica educativa que, como una cultura compartida, es también un elemento importante que compone el habitus, en que el aprendizaje ocurre y las decisiones educativas-metodológicos se realizan. Resaltamos que concebir la docencia como fruto de la trayectoria social a partir de disposiciones híbridas de habitus puede constituirse como una herramienta importante para nuestras formas de actuar en cursos de formación docente y en la elaboración de políticas públicas para esa área.

Palabras-clave: Habitus. La socialización. La formación del profesorado.

\section{Introdução}

No campo da educação, Bourdieu figura como uma importante referência para análise de diferentes temas. No que se refere à apropriação do pensamento do autor no campo acadêmico brasileiro, Loyola (2002) afirma que capital cultural foi o conceito mais utilizado e A Reprodução, de 1975, a obra mais citada nos estudos referentes à educação. Já em outro levantamento, Knoblauch e Penna (2007) destacam que habitus é o conceito mais citado. Em ambos os casos é possível relacionar com a análise de Catani, Catani e Pereira (2001) que indicam que o modo de apropriação do modus operandi do pensamento do autor, isto é, a apropriação teórico-metodológica do conjunto dos seus conceitos, ainda ocorre em 
menor escala, sendo mais comum uma apropriação incidental ou tópica de apenas alguns conceitos. Por outro lado, Medeiros (2013) indica que há um cuidado por parte de alguns programas da pós-graduação do país em sistematicamente apresentar defesas de dissertações e teses, o que revela um esforço de maior rigor conceitual para com o pensamento do autor. Segundo a autora, tal referencial é utilizado especialmente em pesquisas que investigam professores e práticas docentes, trajetórias escolares em diferentes níveis e modalidades de formação.

Nesse sentido, o objetivo deste artigo é apontar contribuições do pensamento de Pierre Bourdieu especificamente para os estudos sobre formação de professores, profissionalização e constituição da docência ${ }^{1}$, de modo a trabalhar com o autor e contra ele, seguindo as orientações de Passeron (2005), ou seja, a intenção aqui é a de não repetir apenas os conceitos apresentados por Bourdieu, mas, a partir da sua apropriação e da fecundidade de seu pensamento sociológico, lançar luzes para uma possibilidade de análise para temas e problemas relativos à formação de professores e sua socialização profissional. Assim, além dos estudos do referido autor, nos embasaremos também nas análises de Gimeno Sacristán (1999), Berger e Luckman (1985) e Setton (2002, 2009, 2012). Num primeiro momento, apresentaremos algumas considerações sobre o conceito de habitus e o processo de socialização; em seguida discutiremos a constituição da prática escolar que se converte em senso prático, como fruto do habitus.

\section{Habitus e o processo de socialização}

Como nos constituímos enquanto agentes sociais? Como professores se constroem durante sua trajetória pessoal e profissional? O conceito de habitus, articulado a campo e diferentes capitais, é uma

1 Dado os limites do artigo, não foi possível apresentar dados empíricos. Mas, a título de ilustração, é possível indicar Mondardo (2016), Capponi (2016) e Santos (2016). 
ferramenta analítica interessante, pois é considerado resultado da aliança entre um meio socialmente estruturado e as condições materiais de existência de uma determinada classe (BOURDIEU, 2001a). É fruto de uma ação organizada, inclinada a atuar como estruturas estruturantes. Objetivamente adaptado, o habitus é o gérmen das práticas e representações, que são regulares e reguladas, e que agindo de forma inconsciente e pré-reflexiva, exercem domínio sobre as operações dos agentes.

Ao serem produto e produtores de suas próprias condições de existência, os agentes reproduzem as estruturas objetivas às quais estão submetidos. Assim, mesmo que de forma imperceptível, a raiz do habitus está nas ações estruturadas pelos agentes, que se adaptam às condições objetivas. A aliança entre tais condições e a existência de disposições já incorporadas são responsáveis pelos anseios de vida assim determinados, que já são pré-adaptados às exigências objetivas de sua conjuntura. Assim, são produtoras das estruturas do habitus, que irão nortear as escolhas realizadas durante a vida do agente (BOURDIEU, 2001a).

Nas palavras do autor, o habitus é:

um sistema de disposições duráveis e transponíveis que, integrando todas as experiências passadas, funciona a cada momento como uma matriz de percepções, de apreciações e de ações - e torna possível a realização de tarefas infinitamente diferenciadas, graças às transferências analógicas de esquemas, que permitem resolver os problemas da mesma forma, e às correções incessantes dos resultados obtidos, dialeticamente produzidas por esses resultados (BOURDIEU, 1983, p. 65).

Ou seja, o habitus é produto de todas as ações realizadas pelo agente, mas que são, ao mesmo tempo, produto constante de reestruturações, que tem por matriz as disposições já incorporadas anteriormente, por isso, são em parte permanentes, mas ao mesmo tempo mutáveis. Além disso, a regulação do habitus pressupõe o controle de um código comum entre os habitus dos agentes que o compõem.

Dessa forma, entendemos então, que os conceitos de socialização e socialização profissional se apresentam como ferramenta auxiliar ao 
conceito de habitus, pois, segundo Berger e Luckmann (1985), a socialização é o processo pelo qual o indivíduo é introduzido no mundo objetivado de uma sociedade, ou de um setor da mesma, ou seja, o conceito tem a intenção de explicar como os indivíduos se tornam o que são. Socialização é incorporação duradoura das formas de sentir, pensar e agir do próprio grupo de origem; logo, se concebe o habitus como produto da socialização dos agentes, que compartilham posições e trajetórias, resultando em um ethos de classe, revelando a incorporação de disposições de habitus similares e a pertença em uma só fração de classe (DUBAR, 1997).

A família está no cerne da constituição do habitus, por ser a primeira e principal instância em contato com o indivíduo, que por meio dessa interação, dotada de valores, crenças e costumes, se tornará agente, iniciando, portanto, sua própria socialização. A família é responsável por transferir ao indivíduo, inconscientemente ou não, o capital cultural e o ethos, ou seja, valores implícitos e interiorizados de forma profunda, que irão definir a forma com que o agente agirá frente ao seu próprio capital cultural e à instituição escolar (BOURDIEU, 2001a).

Exposta a esta configuração, aliado aos saberes incorporados por meio da família (socializador primário), a escola exerce influência direta sobre a constituição do habitus da criança, sendo a principal responsável pela socialização secundária. Assim, a socialização secundária surge como uma expansão da primeira, funcionando na interação com os submundos e realidades adquiridas durante a socialização primária, muitas vezes sobrepondo-a (BERGER e LUCKMANN, 1985).

A socialização escolar se difere de outros tipos de socialização por ser concebida pelos pais como indispensável para a formação de seus filhos. Essa socialização varia de acordo com os capitais apresentados pelas famílias e as frações de classe da qual fazem parte. A título de ilustração, é possível destacar que pais das camadas populares esperam uma escolarização com retorno para inserção ao mercado de trabalho, enquanto pais da elite buscam modelos de socialização coerente aos ideais familiares e menos voltados à escolarização (PAIXÃO, 2007). 
Assim, embora apresentem singularidades decorrentes de sua própria socialização, a tendência que se apresenta para os agentes é resultado de aspirações típicas da fração de classe da qual fazem parte, pois lutam para a conservação das estruturas de seu grupo ou melhora de posição no espaço social, por meio de reconversão de capital (BOURDIEU, 2001b).

O agente é, então, fruto de um processo de socialização contínuo, que se estabelece através das relações sociais com o meio social e no meio social, a fim de integrar e constituir os sujeitos, sendo, como menciona Setton (2012, p. 34) "um constante fazer-se, refazer-se, desfazer-se”, isto é, é um processo ininterrupto que promove transformações no modo de ser e estar no mundo.

Segundo a autora, na contemporaneidade há um novo e forte agente socializador que se instaura junto à família e à escola: a pluralidade cultural ampla e diversificada, originária dos meios midiáticos:

Ou seja, a educação no mundo moderno não conta apenas com a participação da escola e da família. Outras instituições, como a mídia, despontam como parceiras de uma ação pedagógica. Para o bem ou para o mal, a cultura de massa está presente em nossas vidas, transmitindo valores e padrões de conduta, socializando muitas gerações. Em uma situação de modernidade, faz-se necessário problematizar as relações de interação, conflitivas ou harmoniosas, entre os espaços socializadores e agentes socializados (SETTON, 2002, p. 109).

Setton (2009) traz a noção de socialização enquanto um fato social total que envolve a todos e manifesta-se nas dimensões: econômica, política, religiosa e estética, considerando sobretudo a experiência individual (história de vida), o que gera um habitus híbrido (formado por disposições provenientes de diferentes campos complementares ou antagônicos entre si), e que possibilita compreender o sujeito como um todo e não a partir de um aspecto específico, ou seja, o sujeito se constitui da relação de múltiplas experiências em diferentes campos e envolve diversos aspectos (físico, psicológico, cognitivo, social e cultural), não sendo possível dissociá-los para sua análise. 
Considera-se que o processo de socialização das formações atuais é um espaço plural de múltiplas referências identitárias. Ou seja, a contemporaneidade caracteriza-se por oferecer um ambiente social em que o indivíduo encontra condições de forjar um sistema de referências que mescle as influências familiar, escolar e midiática (entre outras), um sistema de esquemas coerente, no entanto híbrido e fragmentado. Embora se saiba que, no contexto atual, cada uma das instâncias formadoras desenvolve campos específicos de atuação, lógicas e valores éticos e morais distintos, considera-se ainda que são os próprios indivíduos quem tecem as redes de sentido que os unificam em suas experiências de socialização (SETTON, 2009, p. 297).

É a partir da mescla de influências de diferentes campos sociais e das experiências pessoais dos sujeitos que temos a constituição do habitus defendido por Bourdieu (1983). Ele enfatiza a necessidade de compreensão do habitus a partir das instituições de socialização que constituem o sujeito.

Tais apontamentos contribuem para a compreensão da constituição da docência e de sua formação de forma ampliada. Segundo Marcelo Garcia (1999), o processo de formação docente tem início já no momento em que os professores são alunos da educação básica, identificada como fase pré-treino; passando pela fase da formação inicial, a entrada à universidade ou preparo formal à docência; fase de iniciação, ao ingressar na profissão, e fase da formação permanente, conhecida no Brasil por formação continuada, correspondente ao desenvolvimento durante a carreira docente.

Os professores da educação básica operam como socializadores secundários, sendo para o aluno referência de ações e valores. Essas representações, durante o processo de socialização dos agentes, passam por avaliações críticas sobre a conduta de seus professores e, ainda que inconscientemente, irão incorporar ou negar algumas dessas disposições (NUNES, 2001), iniciando, portanto, seu processo de socialização profissional.

Como nos tornamos professores? A partir do conhecimento teórico construído na formação docente? Na prática, exercendo o "papel" de professor? Na interação e socialização com outros professores? Enquanto 
alunos, na observação de nossos professores? Gimeno Sacristán (1999, p. 73) afirma que "o professor, como artesão, faz-se no ofício, em contato com a obra”. Nesse sentido, para compreendermos a constituição do professor, requer compreendê-lo não apenas enquanto profissional, mas em todas as suas dimensões.

Nesse sentido, Gimeno Sacristán corrobora as indicações já destacadas por Marcelo Garcia: "A primeira aprendizagem para comportar-se como professor é uma aprendizagem por socialização como aluno, experiência da qual se extraem as primeiras representações da prática que mais tarde, podem ser utilizadas e reproduzidas (GIMENO SACRISTÁN, 1999, p. 53)".

Vale destacar que esse importante momento de formação docente já fora apontado por Lortie (1975). Segundo o autor, tal "aprendizado por observação" ou "socialização antecipatória" exerceria maior influência do que o período de formação inicial. No entanto, em levantamento de estudos sobre socialização profissional docente, Zeichner e Gore (1990) afirmam que há um conjunto expressivo de trabalhos que questionam essa influência, especialmente aqueles que focalizam a carreira docente e o momento de preparação inicial, sobretudo quando pretendem analisar o chamado currículo oculto desses cursos.

Desta forma, destaca-se que, na constituição do habitus, as primeiras experiências são fundamentais, pois servem de base diante de novas situações, estabelecendo um comparativo, avaliando, recusando ou selecionando ações pertinentes à sua lógica. Novas experiências, entretanto, colaboram para possíveis reorganizações de habitus, tendo em vista que:

[...] o habitus adquirido na família está no princípio da estruturação das experiências escolares (em particular, da recepção e assimilação da mensagem propriamente pedagógica), o habitus transformado pela ação escolar, que é diversificada, por sua vez está no princípio da estruturação de todas as experiências ulteriores (como a recepção e assimilação das mensagens produzidas e difundidas pela indústria cultural, ou experiências profissionais) e assim por diante, de reestruturação em reestruturação (BOURDIEU, 1983, p. 80, grifos nossos). 
Sobre esse aspecto, Setton (2005) afirma que as indicações de Berger e Luckmann (1985) sobre socialização primária e secundária precisam ser acrescidas de outros agentes socializadores, tendo em vista que para os autores esse processo teria fim com o ingresso a um grupo profissional. Mas, se considerarmos o conceito de habitus, tal como descrito acima, é um processo contínuo e a partir de múltiplos agentes socializadores.

\section{Prática pedagógica e senso prático}

No que se refere à prática pedagógica, Gimeno Sacristán (1999) a considera como um conjunto de ações que se consolidaram ao longo do tempo no interior das escolas e que organizam novas ações, pois como tradição acumulada, a prática é incorporada na forma de habitus, orientando assim, novas ações e dispensando o sujeito de um planejamento inicial para determinadas situações. Isso porque:

O habitus produz ações e reproduz práticas, porque o esquema gerado historicamente assegura sua presença no futuro pelas de formas de perceber, de pensar, de fazer e de sentir. Uma vez assumido, o habitus tem mais força que qualquer norma formal, porque foi interiorizado e, graças a isso, a reprodução da prática passa desapercebida, simplesmente atuando sob as condições nas quais foi configurada. Sem que isso seja evidente, ele coloca à nossa disposição o acervo cultural que cobre, a tal ponto que o mesmo parece dotado de uma certa autonomia e de relativa independência. Assumimos e reproduzimos a prática com todo o capital cultural depositado com toda a naturalidade, sem sentirmo-nos forçados (GIMENO SACRISTÁN, 1999, p. 84).

É preciso destacar, então, a historicidade presente na constituição das práticas, de modo que experiências passadas são incorporadas e se constituem como base para novas ações. Ou seja, embora o sujeito tenha a opção de recriar ou reinventar suas práticas, o senso prático, guiado pelas experiências prévias, orienta e direciona suas escolhas estabelecendo 
um elo entre passado e presente. O senso prático produzido pelo habitus possibilita o ajuste a novas situações de forma natural, de maneira sensata, objetiva e inconsciente.

Essas considerações acerca do habitus e do senso prático nos levam a pensar que a prática dos professores no dia a dia é decorrente, também, de suas experiências, de sua trajetória de vida, de sua história enquanto sujeitos sociais, considerando diversas dimensões.

Gimeno Sacristán (1999) aborda a necessidade da intencionalidade enquanto condição para ação do professor. Porém, para o autor, o professor deve ter um propósito, um motivo, um fim para impulsionar suas ações tendo consciência de sua prática. Ele menciona que inúmeras são as razões que impulsionam as ações sendo estas distintas entre os sujeitos, uma vez que os sujeitos são históricos, contextualizados, pertencentes a diferentes culturas e meios sociais. Suas ações podem ser motivadas ou orientadas por influências emocionais, afetivas, sociais, culturais, econômicas, políticas, ideológicas, intelectuais, enfim, por inúmeros fatores que sobrepostos o constituem e determinam suas ações direcionando consequentemente sua forma de pensar e estar no mundo.

Assim, a ação tem caráter aberto e pessoal e por isso:

Movem-nos motivos que satisfazem necessidades pessoais e outros assumidos da cultura e das normas sociais e das instituições, que não são conscientes, para todos e para cada um de nós em todos momentos. Uma via de racionalizar a ação para cada um de nós será a de ir adquirindo consciência sobre esse componente implícito que nos impulsiona (GIMENO SACRISTÁN, 1999, p. 34).

O autor, ao mencionar a necessidade de "consciência sobre esse componente implícito que nos impulsiona" considera prévias as disposições do habitus na tomada de decisões, nas escolhas, nas ações, pois uma vez interiorizado ele regula as ações como um sentido prático.

Segundo ele, a prática pertencente ao âmbito social e movida pelo senso prático, é cultura compartilhada, conhecimentos estratégicos, saberes, motivações e desejos também compartilhados. O conhecimento 
adquirido, as experiências vividas forjam a identidade, constituem e modelam o sujeito, fundamentam um estilo próprio e possibilitam um equilíbrio quanto às futuras ações. Para o autor, é preciso considerar a história, a trajetória de vida do sujeito, pois sua prática se ancora em experiências pessoais, sentimentos, isto é, tem também uma história.

Em educação, não podemos falar de condutas cuja objetividade possa ser observada à margem dos atores que as desenrolam, porque, a rigor, não se trata de condutas que respondem a estímulos, mas de ações de sujeitos com biografia e história pessoal e coletiva, aspectos que não se tornam evidentes na apreciação "objetiva', a partir do exterior (GIMENO SACRISTÁN, 1999, p. 32).

Portanto, não é possível compreender a ação educativa sem compreender os sujeitos que praticam as ações. Isso significa que, embora o sujeito possua conhecimento teórico-científico, suas ações serão pautadas no referencial existente nas disposições do habitus, tal como explicado anteriormente.

Para Gimeno Sacristán (1999, p. 35) a ação é orientada e estabilizada por esquemas afetivos e componentes cognitivos que dão uma constância, evitando fazer repetidas considerações para as ações semelhantes, não sendo preciso reinventá-las ou "explicar suas intenções". Temos, portanto, um senso prático no qual entram em ação as disposições de um habitus que dão sentido ao agir.

$\mathrm{O}$ autor ainda menciona que a ação é resultado de uma triangulação entre componente cognitivo (consciência, conhecimento pessoal), componente prático (experiência do saber fazer pessoal) e componente dinâmico (motivos, intenções) sendo cada ação motivada por um ou mais componentes. Assim, poderíamos afirmar que as escolhas ou decisões tomadas pelo indivíduo são provenientes desta triangulação (conhecimento/experiência prática/disposições do habitus).

Mas, segundo o autor, no decorrer do tempo acabamos assumindo uma forma de agir contínua, estável que pode dificultar adaptações a novas situações, o que, por um lado, possibilita um equilíbrio, mas também 
de certa forma, um limite para práticas inovadoras. E, embora a estabilidade do habitus não refute o novo ou impeça modificações, ele se adapta de maneira controlada condicionada a partir do que já está incorporado, sob forma de capital de experiência, ou seja, uma forma de saber fazer que irá orientar as ações futuras, num processo de "cristalização das experiências pessoais e compartilhadas” (GIMENO SACRISTÁN, 1999, p. 72). Afinal, aprendemos não apenas com nossas experiências, mas com as experiências dos outros e, desta forma, contribuímos para a cultura comum.

Na mesma direção, Setton (2011) problematiza a noção de um único habitus docente brasileiro, considerando as dimensões continentais de nosso país e as diferenças culturais tradicionais e contemporâneas que convivem conjuntamente, oportunizando matrizes díspares de valores e normas a partir de diferentes agências socializadoras (família, mídia, religião, grupos de amigos etc). Desta forma, argumenta:

[...] é preciso compreender o habitus docente de forma atualizada. Isto é, fruto de um processo amplo, complexo e estruturado com base em uma multiplicidade de experiências formadoras, que resulta em um habitus composto por disposições híbridas. [...]. Não há um único habitus docente, há o resultado de um conjunto heterogêneo de experiências de formação cultural que particulariza cada um (SETTON, 2011, p. 179, 180).

\section{Considerações finais}

O objetivo deste texto foi trazer contribuições do pensamento de Pierre Bourdieu para os estudos que pretendem analisar a formação e profissionalização de professores, assim como sua prática, a partir de referencial sociológico sobre socialização.

Vale destacar que ainda que socialização tenha sido, originalmente, uma noção utilizada por correntes funcionalistas da sociologia, objetivando compreender os processos de adaptação do indivíduo à 
sociedade, uma leitura mais "construtivista" trouxe uma nova abordagem ao conceito, trazendo para a análise a necessária relação interdependente entre indivíduo e sociedade. Nesse sentido, visando à superação de antigas dicotomias, há um esforço mais recente no campo da sociologia em compreender como os indivíduos são produzidos, bem como um esforço em refletir sobre a condição de produtores das condições sociais que os produzem, numa relação dialética (SETTON, 2012; DUBAR, 1997).

Essa discussão, quando transposta para o campo da formação e prática docentes, pode contribuir ao considerar que a docência é fruto da trajetória social composta por diferentes agências socializadoras, as quais podem ser complementares entre si ou não. Outro componente importante é a própria prática educativa que, como cultura compartilhada, também é um importante elemento que compõem o habitus, a partir do qual o aprendizado ocorre e as decisões didático-metodológicas são tomadas.

Assim, consideramos que há uma série de temáticas que precisam ser melhor investigadas a fim de construirmos um referencial mais adensado sobre a formação e profissionalização docentes, especialmente no que se refere à identificação de agências socializadoras que atualmente convivem com a formação inicial, com o reconhecimento de motivações para escolhas metodológicas em sala de aula e com a articulação entre processos de formação continuada e práticas já estabelecidas, entre outros temas. Tal adensamento se mostra necessário tendo em vista que, conceber a docência como fruto da trajetória social a partir de disposições híbridas de habitus, pode se constituir como uma ferramenta importante para nossas formas de atuar em cursos de formação docente e na elaboração de políticas públicas para essa área.

\section{Referências}

2 O conceito está sendo usado com o mesmo sentido apontado por Corcuff (2001), ou seja, o autor considera uma nova forma de conceber o social, a partir da superação de antigas antinomias presentes nas ciências sociais, tais como micro e macro, objetivo e subjetivo, entre outras. 
BERGER, P. L.; LUCKMANN, T. A construção social da realidade. Petrópolis: Vozes, 1985.

BOURDIEU, P. Esboço de uma teoria da prática. In: ORTIZ, R. (org).; Sociologia. Trad. Paulo Montero e Alicia Auzmendi. São Paulo: Ática, 1983. p. 46-81.

BOURDIEU, P. Futuro de classe e causalidade do provável. In: NOGUEIRA, M. A. e CATANI, A. (orgs.). Escritos de Educação. $3^{\text {a }}$ ed. Petrópolis: Vozes, 2001a. p. 81-126.

BOURDIEU, P. Classificação, desclassificação, reclassificação. In: NOGUEIRA, M. A. e CATANI, A. (orgs.). Escritos de Educação. $3^{\mathrm{a}}$ ed. Petrópolis: Vozes, 2001b. p. 145-183.

CAPPONI, L. A. M. A relação entre as disposições presentes nos habitus e as escolhas didático-metodológicas de professoras da educação infantil para o ensino da linguagem escrita. 118f. Dissertação (Mestrado em Educação) - Setor de Educação, Universidade Federal do Paraná, 2016.

CATANI, A. M.; CATANI, D. B.; PEREIRA, G. R. de M. As apropriações da obra de Pierre Bourdieu no campo educacional brasileiro, através de periódicos da área. Revista Brasileira de Educação, n. 17, 2001, p. 63-85.

CORCUFF, P. As novas sociologias: construções da realidade social. Bauru: EDUSC, 2001.

DUBAR, C. A socialização: construção das identidades sociais e profissionais. Trad. Anette Pierrette R. Botelho e Estela Pinto R. Lamas. Portugal: Porto Editora, 1997.

GIMENO SACRISTÁN, J. Poderes instáveis em educação. Trad. Beatriz Affonso Neves. Porto Alegre: Artes Médicas, 1999.

KNOBLAUCH, A.; PENNA, M. G. O. A obra de Pierre Bourdieu em teses e dissertações da Pós-Graduação brasileira: um mapeamento. Revista de Educação (Campinas), v. 1, p. 29-38, 2007. 
LORTIE, D. C. Schoolteacher: a sociolgical study. Chicago: Univerty of Chicago Press, 1975.

LOYOLA, M. Pierre Bourdieu entrevistado por Maria Andréa Loyola. Revista Pensamento Contemporâneo. Rio de Janeiro: UERJ, 2002.

MARCELO GARCIA, Carlos. Formação de professores. Para uma mudança educativa. Porto: Porto Editora, 1999.

MEDEIROS, C. C. C. Pierre Bourdieu, 10 anos depois. Educar em Revista, n. 47, jan/mar, p. 315-328, 2013.

MONDARDO, G. C. Relações entre disposições do habitus de origem e formação inicial no curso de Pedagogia. 115f. Dissertação (Mestrado em Educação) - Setor de Educação, Universidade Federal do Paraná, 2016.

NUNES, J. B. C. A socialização do professor: As influências no processo de aprender a ensinar. Universidad de Santiago de Compostela. Tese (Doutorado em Filosofia e Ciências da Educação) - Santiago de Compostela, Espanha, 2001.

PAIXÃO, L. P. Socialização na escola. In: PAIXÃO, L. P. e ZAGO, N. (orgs.) Sociologia da Educação: pesquisa e realidade brasileira. Petrópolis: Vozes, 2007. p. 222-244.

PASSERON, J. C. Morte de um amigo, fim de um pensador. In: ENCREVÉ, P. e LAGRAVE, R. M. (orgs.) Trabalhar com Bourdieu. Rio de Janeiro: Bertrand Brasil, 2005, 17-91.

SANTOS, R. A. M. Profissionalização da professora alfabetizadora na interface com a socialização profissional: o programa do pacto nacional de alfabetização na idade certa. 200f. Dissertação (Mestrado em Educação) - Setor de Educação, Universidade Federal do Paraná, 2016.

SETTON, M. G. J. A particularidade do processo de socialização contemporâneo. Temposoc.,São Paulo, v.17, n. 2,p.335-350, nov. 2005.Disponívelem: <http://www. scielo.br/scielo.php?script=sci_arttext\&pid=S0103-20702005000200015\& lng=en\&nrm=iso >. Acesso em: 26 Nov. 2015. 
SETTON, M. G. J. A teoria do habitus em Pierre Bourdieu: uma leitura contemporânea. Revista Brasileira de Educação (Impresso), São Paulo, v. 20, n. maio/ago., p. 60-70, 2002.

SETTON, M. G. J. A socialização como fenômeno social total: notas introdutórias sobre a teoria do habitus. Revista Brasileira de Educação (Impresso), v. 14, p. 296307, 2009.

SETTON, M. G. J. Prática docente: algumas questões do campo sociológico. InterMeio Revista do Programa de Pós-Graduação em Educação - UFMS, v. 17, n. 33, p. 175-182, jan./jun.2011

SETTON, M. G. J. A noção de socialização na Sociologia contemporânea. In: SETTON, M. da G. J. Socialização e cultura: ensaios teóricos. São Paulo: Annablume/Fapesp, 2012. p. 17-34.

ZEICHNER, K. M. \& GORE, J. Teacher socialization. In: HOUSTON, W. R. (org.). Handbook of research on teacher education. New York: Macmillan, 1990. p. 329-348.

Recebido: 12/04/2017

Received: 04/12/2017

Aprovado: 04/11/2017

Approved: 11/04/2017 
